\title{
Cardiovascular Diseases in Context: Multilevel Analysis of Risk Factors in India (2004-2014)
}

\author{
Ayantika Biswas $^{1 *}$, S. K. Singh ${ }^{2}$
}

\begin{abstract}
Cardiovascular diseases (CVDs), accounting for approximately half of all deaths due to non-communicable diseases worldwide, have become a major public health concern. The CVD risk is high among the Indian population, as well as varies by geography. The purpose of the current study was to test the independent effects of contextual socioeconomic variables, while adjusting for individual socioeconomic variables on CVD risk factors in India. Data from the $52^{\text {nd }}, 60^{\text {th }}$, and $71^{\text {st }}$ National Sample Survey Office rounds pertaining to social consumption related to health have been utilized for the current study. A four-level multilevel model has been fitted to examine the measured individual, household, community, and district factors on the prevalence of CVDs. District educational attainment, household expenditure quintile, and proportion of district urbanicity have emerged as important factors with few contraindications in terms of traditional directions of association, as opposed to extant literature. Religious and ethnic composition of the communities and districts has also been found to have an impact. To better manage the CVD health of the nation, there is a strong need to focus on community-level and district-level interventions, in addition to individual-level factors. Future research should investigate these factors to account for unexplained variations in CVD management.
\end{abstract}

Keywords: Cardiovascular research, India, Multilevel modeling, Public health, South Asia studies

Asian Pac. J. Health Sci., (2020); DOI: 10.21276/apjhs.2020.7.3.14

\section{INTRODUCTION}

Cardiovascular diseases (CVDs), accounting for approximately half of all deaths due to non-communicable diseases worldwide, have become a major public health concern. ${ }^{[1]}$ Since the last couple of decades, individual-level data have revealed the strong pattern of association of CVDs in industrialized countries. A higher incidence, prevalence, and mortality in the disadvantaged social classes are observed as compared to their better-off counterparts. ${ }^{[2-7]} A$ number of ecologic studies exist which have documented important $\mathrm{CHD}$ variations across communities with varying socioenvironmental characteristics. ${ }^{[8-10]}$ In spite of interesting hypotheses and insights offered by these studies with regard to the relation between community environments and CVD, the studies have been inadequate in drawing inferences at the individual level or even determine the independence of observed community effects from individual-level variables. ${ }^{[1]]}$

As is the case with Western countries, ${ }^{[12,13]}$ CVD risk factors have been well recognized and documented in many developing

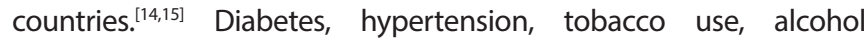
consumption, and being overweight are all well-established CVD risk factors. ${ }^{[16,17]}$ There is also a growing body of literature claiming the increasing prevalence of CVD risk factors as well as their clustering. ${ }^{[18,19]}$ Conventionally, epidemiological studies have been focusing on ascertainment of individual-level factors for diseases. However, a recent gamut of studies has been exploring the population or group (contextual) effects on disease risks. People residing in the same community or context and sharing the same contextual or environmental exposure would be violating the statistical assumption of independence usually employed in regression analysis. Disregard of this adjustment required and, hence, simplistic analysis of contextual independent variables as if they exhibit independent variation across individuals would bias the result, overestimating the association under study. Multilevel modeling provides a solution for simultaneous inclusion of individual- and contextuallevel variables. ${ }^{[20]}$ The independent study of contextual effects from individual variables is also an important facet of public health study.
'Department of Mathematical Demography and Statistics, International Institute for Population Sciences, Mumbai, Maharashtra, India, ${ }^{2}$ Department of Mathematical Demography and Statistics, International Institute for Population Sciences, Mumbai, Maharashtra, India

Corresponding Author: Ayantika Biswas, Department of Mathematical Demography and Statistics, International Institute for Population Sciences, Govandi Station Road (East), Mumbai, Maharashtra - 400 088, India. Tel.: +91-8879491321. E-mail: ayantika111@gmail.com

How to cite this article: Biswas A, Singh SK. Cardiovascular Diseases in Context: Multilevel Analysis of Risk Factors in India (2004-2014). Asian Pac. J. Health Sci., 2020; 7(3):59-69

Source of support: Nil

Conflict of interest: None

Received: 05/05/2020 Revised: 20/06/2020 Accepted: 09/07/2020

Externality is a very good example of a contextual concept. While individual socioeconomic status (SES) determinants such as income, employment details, and educational level have been extensively studied courtesy their role as CVD risk factors, ${ }^{[21-23]}$ the same cannot be said about the SES of the neighborhood. If such effects are actually stronger than that of individual SES, all the residents would have better health if they aim to raise the community SES, as compared to their own, without any sizeable contribution to the society. Likewise, independent effects of individual versus contextual ethnicity are another variable to be taken into consideration while assessing CVD risk factors. The association of ethnicity with CVD risk factors occurs as a result of culture or genetics or both. ${ }^{[24]}$ As culture is contextual, strong contextual ethnic effect is to be expected as the main mechanism. Independent genetic influence can be expressed as an individual effect and is to be kept separate from the ethnicity of the community of the individuals' residence.

Public Health Research has been relating community-level factors to disease and health patterns, ${ }^{[25-27]}$ working off of the assumption of community-level factors being able to affect individual-level 
health outcomes. Several researchers have, since, reiterated the idea of area-level or community-level variables providing information which might not be captured by individual variables. ${ }^{[29-32]}$ Studies in social inequalities in health have utilized area-based measures of socioeconomic characteristics or neighborhood deprivation, ${ }^{[33-35]}$ which have been found to be correlated with health outcomes such as mortality and independent of individual-level indicators. ${ }^{[36,37]}$ Von Korff et al., ${ }^{[38]}$ in a commentary on the potential use of multilevel analysis in epidemiology, have also stressed the need to examine both individual-level and macro-level determinants of risk factors and outcomes, as well as their individual and combined effects in chronic disease epidemiology. Also important is the study of community characteristics on CVD outcomes and risk factors, especially whether they are independent of individual-level characteristics. ${ }^{[9,28]}$ Studies in India have not explored this facet of CVD studies much. Neighborhood environments may affect CHD risk through a variety of mechanisms, the simplest of which may encompass differences in the availability and costs of various food groups, access to recreational spaces, or publicity of tobacco products. Another way neighborhood characteristics might affect individuals' CVD risk that is by variable exposure to stressors, the resources at hand to deal with them, social networks, attitudes, and life expectations. ${ }^{[26,39]}$ Neighborhoods provide settings for social interface, an ambiance from which individuals derive their values, expectations, consumption habits, and market capacities to some extent. Residential delineation is, in turn, intricately linked to social structure as a crucial mediating mechanism, thereby producing and sustaining class relations and social differentiation. ${ }^{[40]}$

India is a country with high variability in the extent of socioeconomic development and ratio of ethnicities among communities. The CVD risk is high among the population, as well as varies by geography. ${ }^{[41]}$ Under this circumstance, the purpose of the current study was to test the independent effects of contextual socioeconomic variables, while adjusting for individual socioeconomic variables on CVD risk factors in the study area. Understanding the community and district characteristics associated with CVD risk factors can enormously aid in health planning and allocation of apt health resources to target areas. ${ }^{[42,43]}$

The study of contextual variables stems from the fact that all members hailing from the same community share the same tenets, which may be unchangeable, e.g., distance from village to school, or modifiable, e.g., availability of health-care services. ${ }^{[49]}$ There may also be cross-level correlation; ${ }^{[36]}$ e.g., economically disadvantaged families mostly living in deprived villages. The event of contextual variables not being factored in analyses risks researchers missing out on modifiable factors which could have benefitted the community at large. If any outcome variable, in this case, occurrence of CVDs, is correlated within a community or neighbourhood, the single-level analysis using common regression methods would underestimate standard errors for contextual effects and bias the results obtained. ${ }^{[38]}$ Multilevel analysis based on linear mixed models help delineate these complex relationships and estimate the effect of factors specified at different levels correctly. The specific objective of this study is to identify the factors at the household, community, and district levels which are independently associated with CVD occurrence.

\section{Materials and Methods}

\section{Study Design}

The surveys pertaining to social consumption related to health, conducted by the National Sample Survey Office (NSSO) are the principal source of data on basic quantitative information on the health sector such as morbidity, hospitalization, receipt of prenatal and postnatal care of women, and expenditure incurred on treatment received from health services in public and private sectors. The information obtained is used extensively for planning, policy formulation, decision support, as well as analytical and research studies by various government organizations, academicians, researchers, and scholars in India. The $52^{\text {nd }}$ round (July 1995-June 1996) and the $60^{\text {th }}$ round (January-June 2004) provided information on the public distribution system, health services, educational services, and problems of the aged.

The schedule for the $71^{\text {st }}$ round (2014) was dedicated to collect information for prevalence rate determination of different ailments by various age-sex groups in different parts of the country, extent of use of health services provided by the government hospitals as well as lower levels of health care institutions, and expenditure incurred on treatment received form public and private health sectors. Furthermore, information on average "out-of-pocket" expenditure for different episodes of illness was collected. The assessment of the role of alternate schools of medicine in prevalence of use, cost of treatment, and type of ailments covered was possible due to the range of questions canvassed in this round. In addition to these, all other questions under various pre-existing heads according to previous rounds of the survey were also canvassed.

\section{First-stage units (FSUs)}

Most states and union territories participated in the survey: A "State sample" was surveyed by state government officials in addition to the "Central sample" surveyed by NSSO. For rural India, the number of villages surveyed in the central sample was 4577 and the number of urban blocks surveyed was 3720 . This document is based on the estimates obtained from the central sample only.

\section{Second-stage units}

Stratification of households was done on the basis of (i) with at least one child of age $<1$ year and (ii) households with at least one member (including deceased former member) hospitalized during the past 365 days. For the survey, from each sample village and urban block, eight households were surveyed. Detailed sampling design and estimation procedure is presented in Appendix $C$ of this document. In 36,480 households in rural areas and 29,452 households in urban areas, this schedule 25.0 schedule was canvassed.

\section{Study Variables}

The variables and their definitions, where required, are listed as follows:

- Dependent variables

The dependent variable is at the individual level.

CVD occurrence: An individual who had a heart disease or high/ low blood pressure in the past 365 days is considered a case.

- Independent variables

- Individual-level independent variables

- Sex and age

- Highest level of education attained: Primary educated or lower secondary level or higher

- Household-level independent variables

- Occupation: Whether employed in labor-intensive jobs or otherwise 
- $\quad$ Religion (wherever available): Hinduism and non-Hinduism

- $\quad$ Ethnicity: Scheduled caste/tribe (SC/ST), non-SC/ST

Table 1: Variations in indicators of cardiovascular diseases occurrence in India, NSSO 52 $2^{\text {nd }}$ round (1995-1996) (169,131 individuals from 6151 primary sampling units in 63 districts)

\begin{tabular}{|c|c|}
\hline Demographic characteristics & $\begin{array}{l}\text { Cardiovascular disease } \\
\text { occurrence }\end{array}$ \\
\hline \multicolumn{2}{|l|}{ Sex } \\
\hline Male & 0.15 \\
\hline Female & 0.4 \\
\hline \multicolumn{2}{|l|}{ Place of residence } \\
\hline Rural & 0.00 \\
\hline Urban & 0.72 \\
\hline \multicolumn{2}{|l|}{ Age } \\
\hline $35-44$ & 0.25 \\
\hline $45-59$ & 0.29 \\
\hline $60-69$ & 0.23 \\
\hline 70 and above & 0.37 \\
\hline \multicolumn{2}{|c|}{ Highest level of education attained } \\
\hline Primary or lower & 0.27 \\
\hline Secondary or higher & 0 \\
\hline \multicolumn{2}{|l|}{ Occupation } \\
\hline Non-labor intensive & 0.39 \\
\hline Labor intensive & 0.16 \\
\hline \multicolumn{2}{|c|}{ Whether belonging to a scheduled caste/tribe household } \\
\hline No & 1.31 \\
\hline Yes & 1.19 \\
\hline \multicolumn{2}{|l|}{ Expenditure quintile } \\
\hline Poorest & 1.8 \\
\hline Poorer & 1.53 \\
\hline Middle & 1.11 \\
\hline Richer & 0.79 \\
\hline Richest & 0.85 \\
\hline \multicolumn{2}{|c|}{$\begin{array}{l}\text { Proportion of population engaged in labor-intensive occupations in } \\
\text { the FSU }\end{array}$} \\
\hline $50 \%$ or less & 0.12 \\
\hline More than $50 \%$ & 0.42 \\
\hline \multicolumn{2}{|c|}{ Proportion of SC/ST population in FSU } \\
\hline $50 \%$ or less & 0.52 \\
\hline More than $50 \%$ & 0.67 \\
\hline \multicolumn{2}{|l|}{ Proportion of district urbanicity } \\
\hline $25 \%$ or less & 0.23 \\
\hline $26-50 \%$ & 0.24 \\
\hline More than $50 \%$ & 0.43 \\
\hline \multicolumn{2}{|c|}{ Proportion of SC/ST population in districts } \\
\hline $25 \%$ or less & 0.18 \\
\hline $26-50 \%$ & 0.29 \\
\hline More than $50 \%$ & 0.02 \\
\hline \multicolumn{2}{|c|}{$\begin{array}{l}\text { Proportion of population engaged in labor-intensive occupations in } \\
\text { the district }\end{array}$} \\
\hline $25 \%$ or less & 0.18 \\
\hline $26-50 \%$ & 0.29 \\
\hline More than $50 \%$ & 0.02 \\
\hline
\end{tabular}

Table 2: Parameter coefficients for the multilevel model for various indicators of cardiovascular diseases occurrence - empty model, without covariates; NSSO $52^{\text {nd }}$ round (1995-1996) (37,758 individuals from 6151 primary sampling units in 63 districts)

\begin{tabular}{lc}
\hline Random effects & Cardiovascular disease \\
\hline Household random variance (SE) & $0.57(0.35)$ \\
HH ICC & 0.61 \\
Community (PSU) random variance (SE) & $4.31(0.43)$ \\
Community (PSU) ICC & 0.54 \\
District random variance (SE) & $0.19(0.1)$ \\
District ICC & 0.02 \\
\hline
\end{tabular}

ICC: Intraclass correlation, PSU: Primary sampling unit, NSSO: National Sample Survey Office
- $\quad$ Expenditure quintile

- $\quad$ Community (FSU)-level independent variables

- Proportion of Hindu households in FSU: $25 \%$ or less, 26-50\%, and more than $50 \%$

- Proportion of population engaged in labor-intensive occupations: $50 \%$ or less of the population, more than $50 \%$

- Educational level attainment

- Proportion of SC/ST population

- District-level independent variables

- Proportion of Hindu population in district

- Proportion of district urbanicity

- Proportion of SC/ST population in districts

- Educational level attainment of district

- Proportion of population engaged in labor-intensive occupations in district

\section{Statistical Analysis}

First, descriptive statistics have been calculated for each of the NSSO rounds under study. The hierarchical structure of the sample, vis-à-vis, individuals nested within communities (PSUs), and PSUs nested within districts, warrants logistic multilevel modeling to be performed in this study. ${ }^{[45-48]}$ Hence, a four-level multilevel model has been fitted to examine the measured individual, household, community, and district factors (fixed effects) on the prevalence of CVDs.

In addition, the household-, community-, and district-level random effects using the melogit command in Stata $15^{[49]}$ have also been estimated. For the outcome variable (CVDs), five models were estimated for each NSSO round. The first model without any covariates represented the total variance in occurrence of CVDs between the households, communities, and districts. For each of the rounds, there is a separate table representing the models with covariates ranging from the individual level (model 1), household

Table 3: Parameter coefficients for the multilevel model for various indicators of cardiovascular diseases occurrence - empty model, without covariates; NSSO $60^{\text {th }}$ round (2004-2005) (126,355 individuals from 7369 primary sampling units in 70 districts)

\begin{tabular}{lc}
\hline Random effects & Cardiovascular disease \\
\hline Household random variance (SE) & $3.58 \mathrm{E}-33(1.98 \mathrm{E}-17)$ \\
HH ICC & 0.52 \\
Community (PSU) random variance (SE) & $3.49(0.39)$ \\
Community (PSU) ICC & 0.52 \\
District random variance (SE) & $0.06(0.04)$ \\
District ICC & 0.01 \\
\hline
\end{tabular}

NSSO: National Sample Survey Office, ICC: Intraclass correlation, PSU: Primary sampling unit

Table 4: Parameter coefficients for the multilevel model for various indicators of cardiovascular diseases occurrence - empty model, without covariates; NSSO $71^{\text {st }}$ round (2014) (113,829 individuals from 8166 primary sampling units in 639 districts)

\begin{tabular}{lc}
\hline Random effects & Cardiovascular disease \\
\hline Household random variance (SE) & $2(0.27)$ \\
HH ICC & 0.42 \\
Community (PSU) random variance (SE) & $0.24(0.18)$ \\
Community (PSU) ICC & 0.06 \\
District random variance (SE) & $0.13(0.05)$ \\
District ICC & 0.02 \\
\hline
\end{tabular}

NSSO: National Sample Survey Office, ICC: Intraclass correlation,

PSU: Primary sampling unit 
level (model 2), community level (model 2), and right up to the district level (model 4). The results of fixed effects (measures of association) have been represented as odds ratios (ORs), along with $95 \%$ confidence intervals. To check the level of correlation of the outcome variable, the intraclass correlation (ICC) was also computed. The random effect results have been represented as ICC. Descriptive statistics as well as multilevel regression models were calculated with the STATA 15.0 statistical package.

\section{Results}

The prevalence of the risk factors categorized by various sociodemographic indicators for the NSSO $52^{\text {nd }}$ round conducted in 1995-1996 is shown in Table 1. A higher percentage of females (0.4\%) are affected by CVDs, as compared to males (0.15\%). FSUs with $50 \%$ or less of their constituent population engaged in labor-intensive occupations had $0.12 \%$ of their population affected by CVDs, while those FSUs which had more than $50 \%$ of their population involved in labor-intensive occupations had $0.42 \%$ of their individuals affected by CVDs. Districts with $25 \%$ or less and between 26 and $50 \%$ of urbanicity each had $0.23 \%$ and $0.24 \%$ of CVD-affected population, as compared to $0.43 \%$ of CVD-affected individuals in districts with more than $50 \%$ of urbanization.

Before assessment of random effects at the household, community, and district-level, the empty models [Tables 2-4] have been presented as means of justifying whether the data warranted

Table 5: Results of the multilevel analysis of the variables related to cardiovascular diseases occurrence in India; NSSO 52 ${ }^{\text {nd }}$ round (1995-1996) $(37,758$ individuals from 6151 primary sampling units in 63 districts)

\begin{tabular}{|c|c|c|c|c|}
\hline \multirow[t]{2}{*}{ Fixed effects } & Model 1 & Model 2 & Model 3 & Model 4 \\
\hline & $\begin{array}{c}\text { Odds ratio (confidence } \\
\text { interval) }\end{array}$ & $\begin{array}{c}\text { Odds ratio (confidence } \\
\text { interval) }\end{array}$ & $\begin{array}{c}\text { Odds ratio (confidence } \\
\text { interval) }\end{array}$ & $\begin{array}{c}\text { Odds ratio (confidence } \\
\text { interval) }\end{array}$ \\
\hline \multicolumn{5}{|l|}{ Individual variables } \\
\hline \multicolumn{5}{|l|}{ Sex } \\
\hline Male & Ref & Ref & Ref & Ref \\
\hline Female & $2.77^{\mathrm{a}}(2.24-3.43)$ & $1.02(0.79-1.31)$ & $1.10(0.86-1.43)$ & $1.1(0.86-1.43)$ \\
\hline \multicolumn{5}{|l|}{ Age } \\
\hline $35-44$ & Ref & Ref & Ref & Ref \\
\hline $45-59$ & $1.17(0.93-1.46)$ & $0.87(0.69-1.1)$ & $0.86(0.69-1.09)$ & $0.86(0.69-1.09)$ \\
\hline $60-74$ & $0.92(0.65-1.31)$ & $0.51^{\mathrm{a}}(0.36-0.74)$ & $0.52^{\mathrm{a}}(0.37-0.76)$ & $0.53^{\mathrm{a}}(0.37-0.76)$ \\
\hline 70 plus & $1.65^{\mathrm{b}}(1.15-2.37)$ & $0.73(0.50-1.07)$ & $0.75(0.52-1.10)$ & $0.76(0.52-1.10)$ \\
\hline \multicolumn{5}{|l|}{ Highest level of education attained } \\
\hline Primary or lower & ref & - & - & - \\
\hline Secondary or higher & $3.66 \mathrm{E}-08$ & - & - & - \\
\hline \multicolumn{5}{|l|}{ Occupation } \\
\hline Non-labor & - & Ref & Ref & Ref \\
\hline Labor & - & $0.55^{\mathrm{a}}(0.42-0.72)$ & $0.79(0.59-1.04)$ & $0.78(0.59-1.04)$ \\
\hline \multicolumn{5}{|l|}{ SC/ST household } \\
\hline No & - & ref & ref & ref \\
\hline Yes & - & $0.94(0.74-1.19)$ & $0.84(0.64-1.1)$ & $0.84(0.64-1.1)$ \\
\hline \multicolumn{5}{|l|}{ Expenditure quintile } \\
\hline Poorest & - & Ref & Ref & Ref \\
\hline Poorer & - & $0.9(0.68-1.20)$ & $0.92(0.69-1.22)$ & $0.92(0.69-1.22)$ \\
\hline Middle & - & $0.65^{a}(0.48-0.89)$ & $0.67^{a}(0.49-0.91)$ & $0.67^{b}(0.49-0.91)$ \\
\hline Richer & - & $0.46^{a}(0.32-0.65)$ & $0.46^{\mathrm{a}}(0.33-0.67)$ & $0.47^{\mathrm{a}}(0.33-0.67)$ \\
\hline Richest & - & $0.5^{\mathrm{a}}(0.35-0.72)$ & $0.52^{\mathrm{a}}(0.37-0.76)$ & $0.53^{\mathrm{a}}(0.37-0.76)$ \\
\hline \multicolumn{5}{|c|}{$\%$ of population engaged in labor-intensive occupations in FSU } \\
\hline $50 \%$ or less & - & - & ref & ref \\
\hline More than 50\% & - & - & $3.1^{\mathrm{a}}(2.27-4.24)$ & $3.12^{\mathrm{a}}(2.28-4.27)$ \\
\hline \multicolumn{5}{|l|}{ Percent of SC/ST population in FSU } \\
\hline $50 \%$ or less & - & - & Ref & Ref \\
\hline More than 50\% & - & - & $1.37(0.97-1.91)$ & $1.38(0.99-1.94)$ \\
\hline \multicolumn{5}{|l|}{ Percent of district urbanicity } \\
\hline $25 \%$ or less & - & - & & \\
\hline $26-50 \%$ & - & - & & $0.91(0.57-1.45)$ \\
\hline More than $50 \%$ & - & - & & $1.56(0.86-2.81)$ \\
\hline \multicolumn{5}{|l|}{ Percent of SC/ST population in districts } \\
\hline $25 \%$ or less & - & - & & $1.3(0.63-2.66)$ \\
\hline $26-50 \%$ & - & - & & $0.13(0.01-1.31)$ \\
\hline \multicolumn{5}{|l|}{ Educational level attainment of district } \\
\hline Low level of educational attainment & - & - & & Ref \\
\hline High level of educational attainment & - & - & & $0.58^{\mathrm{a}}(0.43-0.77)$ \\
\hline \multicolumn{5}{|c|}{$\%$ of population engaged in labor-intensive occupations in the district } \\
\hline$<50 \%$ & - & - & & Ref \\
\hline $50-75 \%$ & - & - & & $0.88(0.64-1.21)$ \\
\hline \multicolumn{5}{|l|}{ Random effects } \\
\hline Household random variance & $0.80(0.39)$ & $0.46(0.34)$ & $0.46(0.34)$ & $0.46(0.34)$ \\
\hline HH ICC & 0.62 & 0.53 & 0.51 & 0.51 \\
\hline Community (PSU) random variance (SE) & $4.45(0.45)$ & $3.1(0.4)$ & $2.9(0.37)$ & $2.9(0.37)$ \\
\hline Community (PSU) ICC & 0.53 & 0.46 & 0.45 & 0.44 \\
\hline District random variance $(\mathrm{SE})$ & $0.21(0.11)$ & $0.09(0.06)$ & $0.09(0.07)$ & $9.33 \mathrm{E}-34(2.06 \mathrm{E}-18)$ \\
\hline District ICC & 0.02 & 0.01 & 0.01 & $1.40 \mathrm{E}-34$ \\
\hline
\end{tabular}

${ }^{a}<0.01$, b0.01-0.05, $0.06-0.1$, ICC: Intraclass correlation, NSSO: National Sample Survey Office, PSU: Primary sampling unit 
Table 6: Variations in indicators of cardiovascular diseases occurrence in India, NSSO 60 ${ }^{\text {th }}$ round (2004-05) (126,355 Individuals from 7369 primary sampling units in 70 districts)

\begin{tabular}{|c|c|}
\hline Demographic characteristics & $\begin{array}{l}\text { Cardiovascular disease } \\
\text { occurrence }\end{array}$ \\
\hline \multicolumn{2}{|l|}{ Sex } \\
\hline Male & 0.61 \\
\hline Female & 0.59 \\
\hline \multicolumn{2}{|l|}{ Place of residence } \\
\hline Rural & 1.05 \\
\hline Urban & 0.00 \\
\hline \multicolumn{2}{|l|}{ Age } \\
\hline $35-44$ & 0.63 \\
\hline $45-59$ & 0.59 \\
\hline $60-74$ & 0.58 \\
\hline 75 and above & 0.59 \\
\hline \multicolumn{2}{|l|}{ Highest level of education attained } \\
\hline Primary or lower & 0.72 \\
\hline Secondary or higher & 0.63 \\
\hline \multicolumn{2}{|l|}{ Occupation } \\
\hline Non-labor intensive & 0.81 \\
\hline Labor intensive & 0.52 \\
\hline \multicolumn{2}{|c|}{ Whether belonging to a Hindu household } \\
\hline No & 0.14 \\
\hline Yes & 3.34 \\
\hline \multicolumn{2}{|c|}{ Whether belonging to a scheduled caste/tribe household } \\
\hline No & 3.23 \\
\hline Yes & 3.4 \\
\hline \multicolumn{2}{|l|}{ Expenditure quintile } \\
\hline Poorest & 4.47 \\
\hline Poorer & 3.57 \\
\hline Middle & 4.22 \\
\hline Richer & 3 \\
\hline Richest & 2.01 \\
\hline \multicolumn{2}{|c|}{ Proportion of Hindu households in FSUs } \\
\hline $25 \%$ or less & 0.43 \\
\hline $26-50 \%$ & 1.06 \\
\hline More than $50 \%$ & 5.48 \\
\hline \multicolumn{2}{|c|}{ Proportion of population engaged in labor-intensive occupations } \\
\hline \multicolumn{2}{|l|}{ in FSU } \\
\hline $50 \%$ or less & 0.55 \\
\hline More than $50 \%$ & 0.94 \\
\hline \multicolumn{2}{|l|}{ Educational attainment of FSU } \\
\hline Low educational attainment & 0.76 \\
\hline High educational attainment & 0.22 \\
\hline \multicolumn{2}{|c|}{ Proportion of SC/ST population in FSU } \\
\hline $50 \%$ or less & 0.6 \\
\hline More than $50 \%$ & 0.7 \\
\hline \multicolumn{2}{|c|}{ Proportion of Hindu population in district } \\
\hline $25 \%$ or less & 0.6 \\
\hline $26-50 \%$ & 1.14 \\
\hline More than $50 \%$ & 1.61 \\
\hline \multicolumn{2}{|l|}{ District urbanicity } \\
\hline $25 \%$ or less & 0.71 \\
\hline 26 to $50 \%$ & 0.62 \\
\hline More than $50 \%$ & 0.52 \\
\hline \multicolumn{2}{|c|}{ Proportion of SC/ST population in districts } \\
\hline $25 \%$ or less & 0.6 \\
\hline $26-50 \%$ & 0.6 \\
\hline \multicolumn{2}{|c|}{ Educational level attainment of district } \\
\hline Low educational attainment & 0.64 \\
\hline High educational attainment & 0.53 \\
\hline \multicolumn{2}{|c|}{$\begin{array}{l}\text { Proportion of population engaged in labor-intensive occupations in } \\
\text { the district }\end{array}$} \\
\hline $25 \%$ or less & 0.41 \\
\hline $26-50 \%$ & 0.61 \\
\hline
\end{tabular}

PSU: Primary sampling unit, NSSO: National Sample Survey Office, ICC: Intraclass correlation

the analysis intended. A significant amount of variation has been observed in the NSSO $52^{\text {nd }}$ round multilevel empty model [Table
2], the district level ICC being 0.02 , the community-within-district level ICC at 0.54 , while that of $\mathrm{HH}$-within-community at 0.6.

Table 5 shows the results of the multilevel models with individual-, household-, community-, and districtlevel indicators. When controlled for factors at all the levels, middle $(O R=0.67, P<0.01)$, richer $(O R=0.46, P<0.01)$, and the richest quintiles (OR $=0.52 ; P<0.01$ ) have been found to be less likely to have CVDs, as compared to those who are at the most economically disadvantaged position. A higher level of educational attainment at the district level was found to be negatively associated with the same, underlining its importance over well-known effects of individual factors. For the same model, the $\mathrm{HH}$ within community ICC is 0.51 , higher than the community within district ICC of 0.44 .

The prevalence of the risk factors categorized by various sociodemographic indicators for the NSSO $60^{\text {th }}$ round conducted in 2004-2005 is shown in Table 6. Households with labor-intensive occupations have lower prevalence of CVD-affected population $(0.52 \%)$, as compared to households with non-labor-intensive occupations $(0.81 \%)$. FSUs with more than $50 \%$ of their constituent population practicing Hinduism had a higher proportion $(5.48 \%)$ of CVD-affected individuals, while those between 26 and $50 \%$ of their population practicing Hinduism had $1.06 \%$ of CVD-affected individuals. The districts with $25 \%$ or less of their constituent population engaged in labor-intensive occupations had $0.41 \%$ of their population affected by CVDs, while those with $26-50 \%$ of their population involved in labor-intensive occupations had $0.61 \%$ of their individuals affected by CVDs.

Table 3 is the empty model with no covariates for assessment of random effects at the household, community, and district level for NSSO $60^{\text {th }}$ round (2004-2005), which shows a significant amount of variation, the district-level ICC being 0.01 , the community within district-level ICC at 0.52 , while that of $\mathrm{HH}$ within community also at 0.52 .

Table 7 shows the results of the multilevel models with individual-, household-, community-, and district-level indicators. Model 1 with only individual factors shows secondary or higher level educated individuals at a lower likelihood $(O R=0.30, P<0.01)$ to be affected by CVDs, as compared to their primary level or lower educated counterparts. Although, when controlled for factors at all the levels, educational attainment at the individual level does not show significant results, but at the community level, a higher level of educational attainment was found to be negatively associated with likelihood of having CVDs, underlining its importance over well-known effects of individual factors. The $\mathrm{HH}$-within-community ICC was found to be 0.39 for the last model which encompassed individual-, $\mathrm{HH}_{-}$, community-, and districtlevel factors.

The prevalence of the risk factors categorized by various sociodemographic indicators for the NSSO $71^{\text {st }}$ round conducted in 2014 is shown in Table 8. Communities with a high level of educational attainment have $0.01 \%$ of CVD-affected individuals, while the occurrence stands at $0.02 \%$ of individuals for communities with low educational attainment. Districts with more than $50 \%$ of their population practicing Hinduism have $0.01 \%$ of their population battling the condition, while those with $25 \%$ or less of their population practicing Hinduism have a higher proportion (0.03) of their population with CVDs. High educational attainment in districts had $0.02 \%$ of the individuals with CVDs, while districts with low educational attainment found 0.01 of their individuals with CVDs. 
Table 7: Results of the multilevel analysis of the variables related to cardiovascular diseases occurrence in India, NSSO 60 th round (2004-05) (126,355 individuals from 7369 primary sampling units in 70 districts)

\begin{tabular}{|c|c|c|c|c|}
\hline Fixed effects & $\begin{array}{c}\text { Model } 1 \\
\begin{array}{c}\text { Odds ratio (confidence } \\
\text { interval) }\end{array}\end{array}$ & $\begin{array}{c}\text { Model } 2 \\
\text { Odds ratio (confidence } \\
\text { interval) }\end{array}$ & $\begin{array}{c}\text { Model } 3 \\
\begin{array}{c}\text { Odds ratio (confidence } \\
\text { interval) }\end{array}\end{array}$ & $\begin{array}{c}\text { Model } 4 \\
\begin{array}{c}\text { Odds ratio (confidence } \\
\text { interval) }\end{array}\end{array}$ \\
\hline \multicolumn{5}{|l|}{ Individual variables } \\
\hline \multicolumn{5}{|l|}{ Sex } \\
\hline Male & Ref & Ref & Ref & Ref \\
\hline Female & $0.91(0.79-1.06)$ & $0.98(0.83-1.15)$ & $0.99(0.84-1.16)$ & $0.99(0.84-1.16)$ \\
\hline \multicolumn{5}{|l|}{ Age } \\
\hline $35-44$ & Ref & Ref & Ref & Ref \\
\hline $45-59$ & $0.90(0.76-1.07)$ & $0.95(0.79-1.15)$ & $0.95(0.79-1.15)$ & $0.95(0.79-1.15)$ \\
\hline $60-74$ & $0.86(0.71-1.05)$ & $0.97(0.78-1.20)$ & $0.97(0.78-1.21)$ & $0.97(0.78-1.21)$ \\
\hline 75 plus & $0.85(0.59-1.23)$ & $1.12(0.74-1.70)$ & $1.13(0.75-1.71)$ & $1.12(0.74-1.70)$ \\
\hline \multicolumn{5}{|l|}{ Highest level of education attained } \\
\hline Primary or lower & Ref & Ref & Ref & Ref \\
\hline Secondary or higher & $0.30^{\mathrm{a}}(0.17-0.51)$ & $0.92(0.50-1.68)$ & $1.29(0.70-2.38)$ & $1.29(0.70-2.37)$ \\
\hline \multirow{2}{*}{\multicolumn{5}{|c|}{ Household-level variables }} \\
\hline & & & & \\
\hline Labor & - & Ref & Ref & Ref \\
\hline Non-labor & - & $0.94(0.78-1.12)$ & $0.98(0.82-1.17)$ & $0.98(0.81-1.17)$ \\
\hline \multicolumn{5}{|l|}{ SC/ST household } \\
\hline No & - & Ref & Ref & Ref \\
\hline Yes & - & $1.01(0.84-1.22)$ & $0.95(0.75-1.21)$ & $0.95(0.75-1.20)$ \\
\hline \multicolumn{5}{|l|}{ Expenditure quintile } \\
\hline Poorest & - & Ref & Ref & Ref \\
\hline Poorer & - & $0.78(0.61-1.01)$ & $0.80(0.62-1.03)$ & $0.80(0.62-1.04)$ \\
\hline Middle & - & $0.92(0.71-1.18)$ & $0.95(0.74-1.23)$ & $0.95(0.74-1.23)$ \\
\hline Richer & - & $0.66^{a}(0.51-0.85)$ & $0.74^{\mathrm{b}}(0.58-0.96)$ & $0.75^{\mathrm{b}}(0.58-0.97)$ \\
\hline Richest & - & $0.45^{\mathrm{a}}(0.34-0.59)$ & $0.61^{\mathrm{a}}(0.46-0.81)$ & $0.62^{\mathrm{a}}(0.46-0.82)$ \\
\hline \multicolumn{5}{|l|}{ Community-level variables } \\
\hline \multicolumn{5}{|l|}{ Proportion of Hindu households in FSU } \\
\hline $25 \%$ or less & - & - & Ref & Ref \\
\hline $26-50 \%$ & - & - & $1.02(0.72-1.44)$ & $1.06(0.75-1.49)$ \\
\hline More than $50 \%$ & - & - & $1.75^{\mathrm{a}}(1.39-2.21)$ & $1.84^{\mathrm{a}}(1.45-2.33)$ \\
\hline \multicolumn{5}{|c|}{ Proportion of population engaged in labor-intensive occupations } \\
\hline $50 \%$ or less & - & - & Ref & Ref \\
\hline More than $50 \%$ & - & - & $1.13(0.89-1.44)$ & $1.12(0.88-1.43)$ \\
\hline \multicolumn{5}{|l|}{ Educational level attainment } \\
\hline Low level of educational attainment & - & - & Ref & Ref \\
\hline High level of educational attainment & - & - & $0.38^{\mathrm{a}}(0.28-0.50)$ & $0.38^{\mathrm{a}}(0.29-0.51)$ \\
\hline \multicolumn{5}{|l|}{ Proportion of SC/ST population } \\
\hline $50 \%$ or less & - & - & Ref & Ref \\
\hline More than $50 \%$ & - & - & $0.95(0.72-1.26)$ & $0.95(0.71-1.25)$ \\
\hline \multicolumn{5}{|l|}{ District-level variables } \\
\hline \multicolumn{5}{|l|}{ Proportion of Hindu population in district } \\
\hline $25 \%$ or less & - & - & - & ref \\
\hline $26-50 \%$ & - & - & - & $0.65(0.23-1.84)$ \\
\hline More than $50 \%$ & - & - & - & $0.29(0.05-1.62)$ \\
\hline \multicolumn{5}{|l|}{ Proportion of district urbanicity } \\
\hline $25 \%$ or less & - & - & - & Ref \\
\hline $26-50 \%$ & - & - & - & $0.71(0.47-1.07)$ \\
\hline More than $50 \%$ & - & - & - & $0.65(0.40-1.06)$ \\
\hline Proportion of SC/ST population in districts & & & & \\
\hline $25 \%$ or less & - & - & - & ref \\
\hline $26-50 \%$ & - & - & - & $0.90(0.68-1.20)$ \\
\hline Educational level attainment of district & & & & \\
\hline Low level of educational attainment & - & - & - & Ref \\
\hline High level of educational attainment & - & - & - & $0.97(0.76-1.23)$ \\
\hline Proportion of population engaged in labor & sive occupations in dist & & & \\
\hline$<25 \%$ & - & - & - & Ref \\
\hline $25-50 \%$ & - & - & & $1.45(0.01-0.04)$ \\
\hline Random effects & & & & \\
\hline $\begin{array}{l}\text { Household random variance } \\
\text { HH ICC }\end{array}$ & $\begin{array}{c}2.09 \mathrm{E}-33(4.7 \mathrm{E}-18) \\
0.5\end{array}$ & $\begin{array}{c}1.24 \mathrm{E}-30(1.09 \mathrm{E}-15) \\
0.39\end{array}$ & $\begin{array}{c}5.65 \mathrm{E}-30(2.19 \mathrm{E}-15) \\
0.39\end{array}$ & $\begin{array}{c}4.28 \mathrm{E}-33(8.21 \mathrm{E}-18) \\
0.39\end{array}$ \\
\hline Community (PSU) random variance (SE) & $3.3(0.37)$ & $2.1(0.26)$ & $2.05(0.26)$ & $2.05(0.26)$ \\
\hline Community (PSU) ICC (\%) & 0.5 & 0.39 & 0.39 & 0.39 \\
\hline District random variance (SE) & $0.05(0.04)$ & $0.04(0.03)$ & $0.03(0.03)$ & $0.02(0.02)$ \\
\hline District ICC (\%) & 0.01 & 0.01 & 0.01 & 0.01 \\
\hline
\end{tabular}

${ }^{a}<0.01, b 0.01-0.05,{ }^{c} 0.06-0.1$, NSSO: National Sample Survey Office, ICC: Intraclass correlation, PSU: Primary sampling unit

Table 4 is the empty model with no covariates for assessment of random effects at the household, community, and district level for NSSO $71^{\text {st }}$ round (2014), which shows a significant amount of variation, the district-level ICC being 0.02 , 
Table 8: Variations in indicators of cardiovascular diseases occurrence in India, NSSO $71^{\text {st }}$ round (2014) (113,829 individuals from 8166 primary sampling units in 639 districts)

\begin{tabular}{lc}
\hline Demographic characteristics & $\begin{array}{c}\text { Cardiovascular disease } \\
\text { occurrence }\end{array}$ \\
\hline Sex & 0.02 \\
Male & 0.01 \\
Female & 0.00 \\
Place of residence & 0.72 \\
$\quad$ Rural & \\
Urban & 0.02 \\
Age & 0.02 \\
35-44 & 0 \\
$45-59$ & 0.02 \\
$60-74$ & \\
75 and above & 0.02 \\
Highest level of education attained & 0.01 \\
Primary or lower & \\
Secondary or higher & 0 \\
Occupation & 0.04 \\
Non-labor intensive &
\end{tabular}

Whether belonging to a Hindu household No

Yes 0.03

Whether belonging to a scheduled caste/tribe household

Yes

No

0.02

Expenditure quintile

Poorest

Poorer

Middle

Richer

Richest

Percent of Hindu households in FSU

$25 \%$ or less

26-50\%

More than 50\%

Proportion of population engaged in labor-intensive occupations in FSU

$50 \%$ or less

More than $50 \%$

Educational attainment in the FSU

Low educational attainment

High educational attainment

Proportion of SC/ST population in FSU

$50 \%$ or less

More than $50 \%$

Proportion of Hindu households in district

$25 \%$ or less

26-50\%

More than 50\%

District urbanicity

$25 \%$ or less

26-50\%

More than $50 \%$

Proportion of SC/ST population in districts

$25 \%$ or less

26 to $50 \%$

More than $50 \%$

0.02

0

0.02

0.01

0.02

0.01

0.03

0.01

0.01

0.02

0.01

0.02

0.01

0.02

0.03

Proportion of population engaged in labor-intensive occupations in the district

$50 \%$ or less

0.02

$50-75 \%$

0

Educational attainment in the district

Low educational attainment

High educational attainment

NSSO: National Sample Survey Office,

the community within district-level ICC at 0.06 , while that of $\mathrm{HH}$ within community at 0.42 .
Table 9 presents the results of the multilevel models with individual-, household-, community-, and district-level indicators. Model 1 with only individual factors shows secondary or higher level educated individuals to be at a lower likelihood $(\mathrm{OR}=0.51, P<0.01)$ to be affected by CVDs, as compared to their primary level or lower educated counterparts. The model with both individualand household-level factors showed that at the household level, expenditure quintiles show results of the nature of the households from richer $(O R=0.61, p<0.01)$ and the richest quintiles $(O R=0.42$; $P<0.01$ ) being less likely to have CVDs, as compared to those who are at the most economically disadvantaged position. At the community level, communities with higher level of educational attainment were 1.6 times more likely $(\mathrm{OR}=1.55, P<0.01)$ to have CVD-affected individuals, as compared to those communities with lower educational attainment. At the district level, model 4 shows urbanicity as an important factor; districts with $26-50 \%$ of their population urbanized 1.4 times more likely $(O R=1.42, P<0.05)$ to have CVDs, as compared to those with $25 \%$ or less of their population urbanized. The districts with more than $50 \%$ of their population urbanized were found to be 2.4 times more likely (OR $=2.40, P<0.01)$, as compared to those districts with $25 \%$ or less of its population urbanized. The HH-within-community ICC was found to be 0.57 for the last model which encompassed individual-, $\mathrm{HH}-$, community-, and district-level factors.

\section{Discussion}

This study shows the influence of several geographical and socioeconomic contextual variables exerting independent influence on CVD risk factors. The previous studies have also found a higher prevalence of CVD risk factors among deprived sections of the population. ${ }^{[50]}$ The results of the present study are in line with these findings; a lower odds of economically advantaged population groups to being affected by CVDs, as compared to their economically disadvantaged counterparts, warranting the need for more attention to CVD problems in areas populated by economically disadvantaged groups.

While an inverse relationship between individual education level and CVD factors has been previously reported ${ }_{,}^{[6,51,52]}$ the effect of education at the contextual level, as well as its association with other CVD risk factors, has not been explored much. The studies, which have accomplished this, have found lower-educated individuals more vulnerable to the condition, amidst a higher risk of smoking, as well as increases in systolic blood pressure (SBP) and diastolic BP. The present study showed significant effects of the educational level of the community on CVD occurrence, a higher educational level of the community more likely to be associated with a higher occurrence of CVDs. Educational level may affect the access to healthcare services as well as awareness about the conditions.

Western studies have previously demonstrated the association of deprivation in low-income communities and the increase in various CVD factors, for example, $\mathrm{SBP}_{1}^{[53]}$ overweight, ${ }^{[54]}$ and diabetes. ${ }^{[55]}$ The results of our study agree with the previous findings regarding the protective effect of household expenditure quintile against the CVD risk. This association is with household income and not individual income. Hence, this finding underlines the fact that the contextual lifestyle of the relatively economically disadvantaged communities must be investigated and intervention applied accordingly. Public awareness about health issues might be more common in higher expenditure quintiles, 
Table 9: Results of the multilevel analysis of the variables related to cardiovascular disease occurrence in India, NSSO $71^{\text {st }}$ round (2014) (113,829 individuals from 8166 primary sampling units in 639 districts)

\begin{tabular}{|c|c|c|c|c|}
\hline \multirow[t]{2}{*}{ Fixed effects } & Model 1 & Model 2 & Model 3 & Model 4 \\
\hline & $\begin{array}{c}\text { Odds ratio } \\
\text { (confidence interval) }\end{array}$ & $\begin{array}{c}\text { Odds ratio } \\
\text { (confidence interval) }\end{array}$ & $\begin{array}{c}\text { Odds ratio } \\
\text { (confidence interval) }\end{array}$ & $\begin{array}{c}\text { Odds ratio (confidence } \\
\text { interval) }\end{array}$ \\
\hline \multicolumn{5}{|l|}{ Individual variables } \\
\hline \multicolumn{5}{|l|}{ Sex } \\
\hline Male & Ref & Ref & Ref & Ref \\
\hline Female & $0.82^{\mathrm{a}}(0.73-0.94)$ & $0.96(0.82-1.13)$ & $0.96(0.82-1.12)$ & $0.95(0.82-1.11)$ \\
\hline \multicolumn{5}{|l|}{ Age } \\
\hline $35-44$ & Ref & Ref & Ref & Ref \\
\hline $45-59$ & $0.90(0.78-1.04)$ & $0.99(0.82-1.20)$ & $1.00(0.84-1.20)$ & $0.99(0.84-1.19)$ \\
\hline $60-74$ & $0.86(0.72-1.03)$ & $0.91(0.72-1.16)$ & $0.97(0.78-1.21)$ & $0.97(0.78-1.20)$ \\
\hline 75 and above & $0.74(0.54-1.03)$ & $1.02(0.67-1.55)$ & $1.05(0.71-1.55)$ & $1.02(0.69-1.50)$ \\
\hline \multicolumn{5}{|l|}{ Highest level of education attained } \\
\hline Primary or lower & ref & ref & ref & ref \\
\hline Secondary or higher & $0.51^{\mathrm{a}}(0.44-0.59)$ & $0.92(0.76-1.13)$ & $0.91(0.75-1.10)$ & $0.89(0.74-1.08)$ \\
\hline \multicolumn{5}{|l|}{ Occupation } \\
\hline Non-labor intensive & - & Ref & Ref & Ref \\
\hline Labor intensive & - & $2.55^{\mathrm{a}}(2.04-3.19)$ & $2.26^{\mathrm{a}}(1.82-2.81)$ & $2.22^{\mathrm{a}}(1.79-2.76)$ \\
\hline \multicolumn{5}{|l|}{ Christian households } \\
\hline No & & Ref & Ref & Ref \\
\hline Yes & & $2.22^{\mathrm{a}}(1.55-3.16)$ & $0.70^{\mathrm{b}}(0.51-0.98)$ & $0.80(0.58-1.11)$ \\
\hline \multicolumn{5}{|l|}{ SC/ST household } \\
\hline No & - & Ref & Ref & Ref \\
\hline Yes & - & $1.13(0.93-1.36)$ & $0.94(0.77-1.16)$ & $0.96(0.78-1.18)$ \\
\hline \multicolumn{5}{|l|}{ Expenditure quintile } \\
\hline Poorest & - & Ref & Ref & Ref \\
\hline Poorer & - & $1.10(0.88-1.39)$ & $1.14(0.92-1.41)$ & $1.15(0.93-1.41)$ \\
\hline Middle & - & $0.94(0.74-1.18)$ & $1.03(0.83-1.27)$ & $1.03(0.83-1.27)$ \\
\hline Richer & - & $0.61^{\mathrm{a}}(0.46-0.81)$ & $0.75^{b}(0.58-0.97)$ & $0.74^{\mathrm{b}}(0.58-0.96)$ \\
\hline Richest & - & $0.42^{\mathrm{a}}(0.30-0.59)$ & $0.56^{\mathrm{a}}(0.40-0.77)$ & $0.55^{\mathrm{a}}(0.40-0.75)$ \\
\hline \multicolumn{5}{|l|}{ Community-level variables } \\
\hline \multicolumn{5}{|l|}{ Proportion of Hindu households in FSU } \\
\hline $25 \%$ or less & - & - & ref & ref \\
\hline $26-50 \%$ & - & - & $0.19^{\mathrm{a}}(0.12-0.27)$ & $0.21^{\mathrm{a}}(0.14-0.31)$ \\
\hline More than $50 \%$ & - & - & $0.11^{\mathrm{a}}(0.09-0.14)$ & $0.14^{\mathrm{a}}(0.11-0.17)$ \\
\hline \multicolumn{5}{|c|}{ Proportion of population engaged in labor-intensive occupations in FSU } \\
\hline $50 \%$ or less & - & - & Ref & Ref \\
\hline More than $50 \%$ & - & - & $1.23(0.95-1.60)$ & $1.25(0.97-1.63)$ \\
\hline \multicolumn{5}{|l|}{ Educational attainment in FSU } \\
\hline Low level of educational attainment & - & - & Ref & Ref \\
\hline High level of educational attainment & - & - & $1.55^{\mathrm{a}}(1.27-1.89)$ & $1.53^{\mathrm{a}}(1.25-1.87)$ \\
\hline Percent of SC/ST population in FSU & & & & \\
\hline $50 \%$ or less & - & - & ref & ref \\
\hline More than $50 \%$ & - & - & $1.19(0.92-1.56)$ & $1.36^{\mathrm{b}}(1.04-1.78)$ \\
\hline Percent of Hindu population in the district & & & & \\
\hline $25 \%$ or less & - & - & - & ref \\
\hline $26-50 \%$ & - & - & - & $0.91(0.67-1.24)$ \\
\hline More than $50 \%$ & - & - & - & $0.97(0.67-1.39)$ \\
\hline Percent of district urbanicity & & & & \\
\hline $25 \%$ or less & - & - & - & ref \\
\hline $26-50 \%$ & - & - & - & $1.42^{\mathrm{b}}(1.01-2)$ \\
\hline More than $50 \%$ & - & - & - & $2.40^{\mathrm{b}}(1.61-3.57)$ \\
\hline Percent of SC/ST population in districts & & & & \\
\hline $25 \%$ or less & & & & Ref \\
\hline $26-50 \%$ & - & - & - & $0.77^{\mathrm{b}}(0.62-0.95)$ \\
\hline More than $50 \%$ & - & - & - & $0.53^{\mathrm{a}}(0.36-0.79)$ \\
\hline Educational level attainment of district & & & & \\
\hline Low level of educational attainment & - & - & - & Ref \\
\hline High level of educational attainment & - & - & - & $0.85(0.67-1.07)$ \\
\hline$\%$ of population engaged in labor-intensiv & ions in the district & & & \\
\hline$<50 \%$ & - & - & - & Ref \\
\hline $50-75 \%$ & - & - & - & $0.83(0.62-1.13)$ \\
\hline Random effects & & & & \\
\hline Household random variance & $2.13(0.28)$ & $6.98(1.06)$ & $3.84(0.57)$ & $3.67(0.54)$ \\
\hline $\mathrm{HH} I C C$ & 0.44 & 0.75 & 0.59 & 0.57 \\
\hline Community (PSU) random variance (SE) & $0.28(0.19)$ & $2(0.65)$ & $0.55(0.30)$ & $0.51(0.29)$ \\
\hline Community (PSU) ICC (\%) & 0.07 & 0.22 & 0.1 & 0.09 \\
\hline District random variance (SE) & $0.15(0.06)$ & $0.86(0.18)$ & $0.26(0.09)$ & $0.17(0.08)$ \\
\hline District ICC (\%) & 0.03 & 0.07 & 0.03 & 0.02 \\
\hline
\end{tabular}


which may be the reason of such results. The present study has a large sample size, as well as high response rate, hence, fulfilling the pre-requisites for multilevel modeling. ${ }^{[19]}$

The association between individual-, household-, community-, and district-level factors and the occurrence of CVDs has been examined in this study. For example, $0.4 \%$ of females have been observed to have CVDs as opposed to $0.15 \%$ of males during 1995-96, the difference narrowing down in $2004-2005$ with $0.61 \%$ of males and $0.59 \%$ females affected, and the percentages both decreasing to $0.02 \%$ of males and $0.01 \%$ of females in 2014. Progression across the household wealth quintiles shows a decreasing prevalence of the condition across all the survey periods. The multilevel analysis has underlined the importance of individual-, household-, community-, and district-level factors in the occurrence of CVDs across India. The framework encompassing all the variables at different levels has demonstrated significant effect of community and district variations in the variable under study. The district-level variables except the educational level of the district have not been found to be major influential factors in the occurrence of CVDs much. Some of the variables found to be significant in univariate model became insignificant when adjusted for other variables in the multilevel analysis. The results of this study urge a shift of focus beyond individual factors while examining CVDs. The proportion of district urbanicity has also been found to be an important factor in the determination of CVD risk.

In the $52^{\text {nd }}$ round of the survey, a higher percentage of the population engaged in labor-intensive occupations in the communities saw an increased likelihood of CVD occurrence, and an opposite effect of higher educational attainment of the district, as well as a higher household expenditure quintile was observed on the variable under study.

The $60^{\text {th }}$ round of the NSSO survey saw communities with a higher percentage of individuals practicing Hinduism associated with higher likelihoods of CVD occurrence, while the districts with higher educational attainment had the opposite experience.

In the $71^{\text {st }}$ round of NSSO, there were a plethora of significant factors affecting CVD occurrence, vis-a-vis, a higher proportion of district urbanicity, a higher proportion of scheduled caste or scheduled tribe households in communities, and households engaged in labor-intensive occupations are some factors that have been found to be positively associated with a higher likelihood of CVD occurrence. On the contrary, households with higher expenditure quintiles, higher proportion of households practicing Hinduism in communities, and a higher proportion of scheduled caste or scheduled tribe households in districts are some factors associated with lower likelihood of CVD occurrence.

These findings underline the need for interventions to reduce social inequalities, which combine both individual (e.g., information campaigns and behavioral change communication strategy about benefits of physical activity) and structural prevention (e.g., local activity centers) in communities, aimed at community health improvement.

\section{Conclusion}

The present study sheds light on the global trend of studies increasingly examining CVD risk factors in a contextual setting in addition to individual characteristics, as opposed to only individual and personal lifestyle factors. In Western nations, most of the unfavorable outcomes are concentrated toward the economically disadvantaged groups of the population, the results are echoed in the present study. While contextual socioeconomic status development factors are associated with CVD risk factors, communities with higher educational attainment have been found to more likely to be affected by CVD. Socioeconomic development strategies should take these health effects into account, in the planning stage.

This study went beyond the usual consideration of individual factors and investigated the effects of community- and districtlevel factors on the phenomenon under study. Proportion of district urbanicity has been found to be associated with a higher likelihood of CVD risk in 2014, though, the results are not significant in the earlier two rounds of the survey. Analysis of these factors affecting CVD risk revealed interesting results, which are expected to have important implications for evidence-based strategizing for CVD control policies. District educational attainment, household expenditure quintile, and proportion of district urbanicity have emerged as important factors with a few contraindications in terms of traditional directions of association, as opposed to extant literature. These findings throw light on how strengthening policy measures, while keeping these factors in consideration, can ease the transition of the nation into better health in terms of CVD management.

Religious and ethnic composition of the communities and districts has been found to have an impact, too; case in point, communities with higher proportion of Hindu households are found to be associated with lower likelihood of CVD risk, and districts with higher proportion of scheduled caste and tribe households also have the same relation with CVD risk. Hence, there must be some pathways of action stemming from these compositional differences which need to be explored further in this regard. To better manage the CVD health of the nation, there is a strong need to focus on community-level and districtlevel interventions, in addition to individual-level factors. Future research should investigate these very factors to account for unexplained variations in CVD management. Nonetheless, individual inequalities need to be taken into account when designing interventions because they are strongly related to all types of risk behavior under study.

\section{Conflicts of Interest}

The authors declare no potential conflicts of interest with respect to research, authorship, and/or publication of this article.

\section{Acknowledgments}

The authors are thankful to all the coordinators of National Sample Survey Organization (NNSO), for their relentless support in providing community-based estimates at national and subnational levels.

\section{References}

1. World Health Organization. The World Health Report 2003: Shaping the Future. Geneva: World Health Organization; 2003.

2. Rose G, Marmot MG. Social class and coronary heart disease. Heart 1981;45:13-9.

3. Marmot MG, Stansfeld S, Patel C, North F, Head J, White I, et al. Health inequalities among British civil servants: The Whitehall II study. Lancet 
1991;337:1387-93.

4. Feldman JJ, Makuc DM, Kleinman JC, Cornoni-Huntley J. National trends in educational differentials in mortality. Am J Epidemiol 1989;129:919-33.

5. Pell S, Fayerweather WE. Trends in the incidence of myocardial infarction and in associated mortality and morbidity in a large employed population, 1957-1983. N Engl J Med 1985;312:1005-11.

6. Kaplan GA, Keil JE. Socioeconomic factors and cardiovascular disease: A review of the literature. Circulation 1993;88:1973-98.

7. Diez-Roux AV, Nieto FJ, Tyroler HA, Crum LD, Szklo M. Social inequalities and atherosclerosis the atherosclerosis risk in communities study. Am J Epidemiol 1995;141:960-72.

8. Wing S, Casper M, Davis W, Hayes C, Riggan W, Tyroler HA. Trends in the geographic inequality of cardiovascular disease mortality in the United States, 1962-1982. Soc Sci Med 1990;30:261-6.

9. Wing S, Barnett E, Casper M, Tyroler HA. Geographic and socioeconomic variation in the onset of decline of coronary heart disease mortality in white women. Am J Public Health 1992;82:204-9.

10. Tyroler HA, Wing S, Knowles MG. Increasing inequality in coronary heart disease mortality in relation to educational achievement: Profile of places of residence, United States, 1962 to 1987. Ann Epidemiol 1993;3:S51-4.

11. Piantadosi S, Byar DP, Green SB. The ecological fallacy. Am J Epidemiol 1988;127:893-904.

12. Isomaa BO, Almgren $\mathrm{P}$, Tuomi T, Forsén B, Lahti $\mathrm{K}$, Nissen $\mathrm{M}$, et al. Cardiovascular morbidity and mortality associated with the metabolic syndrome. Diabetes Care 2001;24:683-9.

13. Krauss RM, Winston M, Fletcher BJ, Grundy SM. Obesity: Impact on cardiovascular disease. Circulation 1998;98:1472-6.

14. Cheepudomwit $S$, Chapman N, He J, Neal B, Suriyawongpaisal P, Whelton $\mathrm{P}$, et al. Cardiovascular risk factor levels in urban and rural Thailand: Results from the international collaborative study of cardiovascular disease in Asia (InterASIA). Eur J Cardiovasc Prev Rehabil 2003;10:249-57.

15. Saw SM, Rajan U. The epidemiology of obesity: A review. Ann Acad Med Singapore 1997;26:489-93.

16. Fang XH, Longstreth WT Jr., Li SC, Kronmal RA, Cheng XM, Wang WZ, et al. Longitudinal study of blood pressure and stroke in over 37,000 people in China. Cerebrovasc Dis 2001;11:225-9.

17. Wildman RP, Gu D, Reynolds K, Duan X, Wu X, He J. Are waist circumference and body mass index independently associated with cardiovascular disease risk in Chinese adults? Am J Clin Nutr 2005;82:1195-202.

18. Gu D, Gupta A, Muntner P, Hu S, Duan X, Chen J, et al. Prevalence of cardiovascular disease risk factor clustering among the adult population of China: Results from the international collaborative study of cardiovascular disease in Asia (InterAsia). Circulation 2005; 112:658-65.

19. Gu D, Reynolds K, Wu X, Chen J, Duan X, Reynolds RF, et al, InterASIA Collaborative Group. Prevalence of the metabolic syndrome and overweight among adults in China. Lancet 2005;365:1398-405.

20. Snijders TA, Bosker RJ. Multilevel Analysis: An Introduction to Basic and Advanced Multilevel Modeling. United States: SAGE; 2011.

21. Ezeamama AE, Viali S, Tuitele J, McGarvey ST. The influence of socioeconomic factors on cardiovascular disease risk factors in the context of economic development in the Samoan archipelago. Soc Sci Med 2006;63:2533-45.

22. Ball K, Crawford D. Socioeconomic status and weight change in adults: A review. Soc Sci Med 2005;60:1987-2010.

23. Roohafza HR, Sadeghi M, Kelishadi R. Cardiovascular risk factors in Iranian adults according to educational levels: Isfahan healthy heart program. Asia Pac J Public Health 2005;17:9-14.

24. Sharma S, Malarcher AM, Giles WH, Myers G. Racial, ethnic and socioeconomic disparities in the clustering of cardiovascular disease risk factors. Ethn Dis 2004;14:43-8.

25. Goldberger J, Wheeler GA, Sydenstricker E. A study of the relation of family income and other economic factors to pellagra incidence in seven cotton-mill villages of South Carolina in 1916. Public Health Rep (1896-1970) 1920;35:2673-714.

26. Catalano R. Paradigm succession in the study of public health. In: Health Behavior Community. New York: Pergamon Press; 1979. p. 87-137.

27. Catalano R. The ecological paradigm. In: Health, Behavior, and the Community. New York: Pergamon Press; 1979. p. 64-86.

28. Morgenstern H. Socioeconomic factors: Concepts, measurement, and health effects. In: Workshop on Measuring Psychosocial Variables in Epidemiologic Studies of Cardiovascular Disease. Bethesda: National Institutes of Health; 1985. p. 3-35.

29. Susser M. The logic in ecological: I. The logic of analysis. Am J Public Health 1994;84:825-9.

30. Schwartz $S$. The fallacy of the ecological fallacy: The potential misuse of a concept and the consequences. Am J Public Health 1994;84:819-24.

31. Krieger N, Rowley DL, Herman AA, Avery B, Phillips MT. Racism, sexism, and social class: Implications for studies of health, disease, and wellbeing. Am J Prev Med 1993;9:82-122.

32. Kaplan GA. People and places: Contrasting perspectives on the association between social class and health. Int J Health Serv 1996;26:507-19.

33. Townsend P. Deprivation. J Soc Pol 1987;16:125-46.

34. Townsend P, Phillimore P, Beattie A. Health and Deprivation: Inequality and the North. United Kingdom: Routledge; 1988.

35. Carstairs V, Morris R. Deprivation and health in Scotland. Health Bull 1990;48:162.

36. Anderson RT, Sorlie P, Backlund E, Johnson N, Kaplan GA. Mortality effects of community socioeconomic status. Epidemiology 1997;8:42-7.

37. O'Campo P, Gielen AC, Faden RR, Xue X, Kass N, Wang MC. Violence by male partners against women during the childbearing year: $A$ contextual analysis. Am J Public Health 1995;85:1092-7.

38. Von Korff M, Koepsell T, Curry S, Diehr P. Multi-level analysis in epidemiologic research on health behaviors and outcomes. Am J Epidemiol 1992;135:1077-82.

39. Kennedy DA. Community health and the urban environment. In: The Effect of the Man Made Environment on Health and Behavior. Atlanta, GA: Centers for Disease Control, Public Health Service; 1977. p. 7-44.

40. Harvey D. Class structure in a capitalist society and the theory of residential differentiation. In: Peel R, Chisholm M, Haggett EP, editor. Processes in Physical and Human Geography. London: Heinemann; 1975. p. 354-69.

41. Gupta R, Gupta VP. Meta-analysis of coronary heart disease prevalence in India. Indian Heart J 1996;48:241-5.

42. Merlo J, Yang M, Chaix B, Lynch J, Råstam L. A brief conceptual tutorial on multilevel analysis in social epidemiology: Investigating contextual phenomena in different groups of people. J Epidemiol Community Health 2005;59:729-36.

43. Johnston SC. Combining ecological and individual variables to reduce confounding by indication: Case study-subarachnoid hemorrhage treatment. J Clin Epidemiol 2000;53:1236-41.

44. Pickett KE, Pearl M. Multilevel analyses of neighbourhood socioeconomic context and health outcomes: A critical review. J Epidemiol Community Health 2001;55:111-22.

45. DiPrete TA, Forristal JD. Multilevel models: Methods and substance. Ann Rev Sociol 1994;20:331-57.

46. Goldstein H. Multilevel Statistical Models. London: Wiley; 1995.

47. Duncan C, Jones K, Moon G. Context, composition and heterogeneity: Using multilevel models in health research. Soc Sci Med 1998;46:97-117.

48. Diez-Roux AV. Bringing context back into epidemiology: Variables and fallacies in multilevel analysis. Am J Public Health 1998;88:216-22.

49. Cooperation Society. Stata 15, Stata Cooperation. College Station, TX: Cooperation Society; 2017. 
50. Li LS, Wu W, Ye XL, Zhou QY. Prevalence of hypertension and risk factors in rural Fu Jian Province. Chine J Pract Intern Med 2006;26:697-8.

51. Diez-Roux AV, Nieto FJ, Muntaner C, Tyroler HA, Comstock GW, Shahar E, et al. Neighborhood environments and coronary heart disease: A multilevel analysis. Am J Epidemiol 1997;146:48-63.

52. Gutierrez-Fisac JL, Regidor E, Banegas JB, Artalejo FR. The size of obesity differences associated with educational level in Spain, 1987 and 1995/97. J Epidemiol Community Health 2002;56:457-60.

53. Winkleby MA, Jatulis DE, Frank E, Fortmann SP. Socioeconomic status and health: How education, income, and occupation contribute to risk factors for cardiovascular disease. Am J Public Health 1992;82:816-20.

54. King T, Kavanagh AM, Jolley D, Turrell G, Crawford D. Weight and place: A multilevel cross-sectional survey of area-level social disadvantage and overweight/obesity in Australia. Int J Obes 2006;30:281-7.

55. CDC Diabetes Cost-effectiveness Group. Cost-effectiveness of intensive glycemic control, intensified hypertension control, and serum cholesterol level reduction for Type 2 diabetes. JAMA 2002;287:2542. 